\title{
Thermodynamics of antibiotics: natural cyclodextrin inclusion complex formation and covering of nano-metric calcite with these substances
}

\author{
Konrad Szaruga ${ }^{1}$. Maja Fuz ${ }^{1} \cdot$ Małgorzata Wszelaka-Rylik $^{2}$ [D $\cdot$ Paweł Gierycz ${ }^{1}$
}

Received: 16 December 2019 / Accepted: 6 July 2020 / Published online: 5 August 2020

(c) The Author(s) 2020

\begin{abstract}
Isothermal titration calorimetry (ITC) has been used to characterize inclusion complex formation of natural $(\alpha-, \beta-, \gamma-)$ cyclodextrins with antibiotics (ampicillin—sodium, penicillin G—sodium, streptomycin sulfate) in aqueous solutions. ITC measurements were taken at $298.15 \mathrm{~K}$ on Isothermal Titration Calorimeter Nano ITC. The experimental data were analyzed on the basis of the independent site model. Based on the experimental values of equilibrium constant $(K)$ and enthalpy of complex formation $(\Delta H)$, the Gibbs energy of complex formation $(\Delta G)$ and the entropy of complex formation $(\Delta S)$ have been calculated. The analysis of the obtained inclusion complexes show that independently of the kind of cyclodextrin and antibiotics the obtained equilibrium constants are almost the same, but it is a difference between the changes in enthalpies of complex formation for the investigated systems. The stoichiometry of complexes formed both by ampicillin-sodium and by penicillin G-sodium with all the natural cyclodextrins is the same and equal to 1:1 and the complex formation is entropy driven. Three antibiotics (ampicillin—sodium, penicillin G-sodium and streptomycin sulfate) have been used further for covering of the monodisperse calcium carbonate nanoparticles obtained in the reactor (three-phase reaction) with rotating disks. Three series of experiments have been performed. First was connected with adsorption of the antibiotics on the surface on nano-calcite and two others with intercalation of the drugs into nano-metric $\mathrm{CaCO}_{3}$ structure (aggregates). An intercalation has been performed in two ways: one where the antibiotic was added to the reactor chamber at the beginning of the precipitation reaction and second where it was added just after the end of the reaction. Both pure $\mathrm{CaCO}_{3}$ nanoparticle and antibiotic-coated $\mathrm{CaCO}_{3}$ powders were deeply analyzed by the use of the thermogravimetric and the differential scanning calorimetry method. The performed investigations showed that all the antibiotics used can be both adsorbed and intercalated into the nano-metric $\mathrm{CaCO}_{3}$ obtained in the reactor with rotating disks. The different adsorption obtained by different antibiotics was caused by the different interaction between them and nano-calcite, caused by their different structure. The experimental data have allowed also for distinction between the antibiotics molecules present on calcite surface (adsorption) or antibiotics molecules intercalated into the nano-calcite structure. The conducted research shows that both approaches, i.e., formation of inclusion complexes with natural cyclodextrins and covering (adsorption and intercalation) of nano-metric $\mathrm{CaCO}_{3}$, can be successfully implemented for their pharmaceutical applications.
\end{abstract}

Keywords Isothermal titration calorimetry (ITC) $\cdot$ TG/DSC analyses · Ampicillin—sodium · Penicillin G—sodium · Streptomycin sulfate $\cdot \alpha-, \beta-, \gamma$-cyclodextrin $\cdot$ Inclusion complex $\cdot$ Nano-metric calcium carbonate $\cdot$ Coated $\mathrm{CaCO}_{3}$ with antibiotics

Małgorzata Wszelaka-Rylik

m.wszelaka-rylik@uksw.edu.pl

1 Faculty of Chemical and Process Engineering, Warsaw University of Technology, Warynskiego 1, 00-645 Warsaw, Poland

2 Faculty of Biology and Environmental Sciences, Cardinal Stefan Wyszynski University in Warsaw, Wóycickiego 1/3, 01-938 Warsaw, Poland

\section{Introduction}

One of the novel areas of applicability of PCC (precipitated calcium carbonate) nanoparticles is the pharmaceutical industry where nano-metric $\mathrm{CaCO}_{3}$ is used as a drug carrier. $\mathrm{CaCO}_{3}$ is considered as one of the best drug carriers not only because of its high biocompatibility and biodegradability but also because of its high mechanical and chemical stability 
under physiological conditions. The successful use of nanometric calcium carbonate is determined by its physicochemical properties such as morphology, structure, size, whiteness, oil adsorption and chemical purity. Therefore, many different approaches have been applied for its production [1-15], where one of the most important factors influencing the crystalline phase of calcium carbonate was a properly selected solvent [16]. Besides the knowledge of the structure and properties (surface modification, compatibility, etc.) of the system drug-nano-metric $\mathrm{CaCO}_{3}$ - the control of drug release rate, depending on the size of the particles and their pores, is very important. Combinations of many systems, carrier (nanoparticles of $\mathrm{CaCO}_{3}$ )—drug, have been studied for the last decade [17-32].

Generally, we can define three categories of the surface coating: partial coating, monolayer coating and multilayer (excessive) coating. The most important from the point of view of a precise delivery system seems to be the monolayer coating where we can accurately determine the amount of applying drug. The efficient coating of $\mathrm{CaCO}_{3}$ nanoparticles can be performed by the use of two groups of methods. In the first group, we deal with physical adsorption of organic compounds on the calcium carbonate surface [28-32]. In this case, the adsorption is mainly regulated by electrostatic interactions (on the surface and inside porous calcium carbonate particles) between biomacromolecules and the aggregated $\mathrm{CaCO}_{3}$ particles as well as protein-protein interactions. These methods, including some theoretical studies concerning computer simulation [32], are now widely used and investigated. The second group of investigations is concerned with intercalation (or intercalation and adsorption) of drugs into the nano-metric $\mathrm{CaCO}_{3}$ structure [17-27]. The drugs are entrapped and distributed uniformly in the matrix of $\mathrm{CaCO}_{3}$ microparticles during crystallization [17-27].

Cyclodextrins (CDs) have recently been recognized as useful pharmaceutical excipients. In pharmacy, one of the ways of drug delivery bases on the production of inorganic nano-material cover by drugs or their complexes with CDs. Such supramolecular structure stabilizes deposited system which takes the architectural advantages of particles and the properties of drugs. This explains the wide range of applications of solid-coated drugs in biotechnology or biomedicine.

That is why one of the aims of this work is the isothermal titration calorimetry (ITC) study of inclusion complex formed by natural cyclodextrins ( $\alpha-C D, \beta-C D$ and $\gamma-C D$ ) with antibiotics (ampicillin—sodium, penicillin $\mathrm{G}$-sodium and streptomycin sulfate). The ITC method has been widely used for characterization of drug inclusion complexes with natural cyclodextrins [33-40], but none of the experiments has dealt with the investigated drug. The present work, concerning inclusion complexes formation and characterization of calcium carbonate nanoparticles covered with three antibiotics (ampicillin—sodium, penicillin G—sodium and streptomycin sulfate), is a part of a big project concerning investigation of inclusion complexes formed by different drugs and natural cyclodextrins [12-15, 41-44], which can be further used for covering of nano-metric $\mathrm{CaCO}_{3}$ working as a drug carrier. In the present investigations, we continue our previous works [41-44] dedicated both to investigation of inclusion complexes formation [41-44] and to covering of nano-metric $\mathrm{CaCO}_{3}$ with an organic substance. Our work consists of three parts: first dedicated to thermodynamics of inclusion complexes formation, second dedicated to the adsorption of the antibiotics used on the nano-calcite and third dedicated to the intercalation of the drugs into the nano-metric $\mathrm{CaCO}_{3}$ structure.

\section{Experimental}

\section{Materials and solutions}

The cyclodextrins used in the experiments were of pharmaceutical grade ( $\alpha-C D$ : Cavamax W6 Pharma; $\beta$-CD: Cavamax W7 Pharma; $\gamma$-CD: Cavamax W8 Pharma) and were provided by Wacker Chemie AG (Germany). They were stored in shade at $25^{\circ} \mathrm{C}$ and before experiments were dried in vacuum drier SPU-200 (ZUT COLECTOR, Poland) for $24 \mathrm{~h}$. The cyclodextrin solutions were prepared just before the experiments by weighing on analytical balance RADWAG AS 82/220.X2.

Carbon dioxide used in experiments was taken directly from a gas bottle (99.9993\% pure, from Linde) and calcium hydroxide from a pure sample (p.a. from POCH Gliwice Poland). Chemicals were used without any further purifications.

All samples were prepared using double-distilled and deionized water. The initial concentration of calcium hydroxide that was used for calcium carbonate production was equal to $56 \mathrm{mM}$. The slurry was prepared by dispersing $4.0 \mathrm{~g}$ of $\mathrm{Ca}(\mathrm{OH})_{2}$ powder into deionized water in a $1 \mathrm{dm}^{3}$ of volumetric flask and then well mixed. After 2 days, slurry was treated by ultrasonic bath for $10 \mathrm{~min}$, the solution was cooled down to $25^{\circ} \mathrm{C}$ and immediately used for experiments.

All the antibiotics (ampicillin-sodium, penicillin Gsodium and streptomycin sulfate) were provided by SigmaAldrich Sp. z.o.o. (Poland) and were of pharmaceutical grade.

\section{Precipitation procedures}

In the present experiments, the carbonation process was carried out in multiphase (three-phase: gas-liquid-solid) system using the reactor with rotating disks (RDR) [12-15]. The one reactor chamber that was used in the experiments has a maximum volume of liquid reactant 
equal to $2 \mathrm{~L}$. Each chamber consists of five compartments with five vertical disks installed on common axle enabling rotation, The disks are driven by electric motor Hitachi L100, which enables smooth rotating frequency control from 0 to 200 revolutions per minute. Before each experiment, the reactor elements were cleaned with $10 \%$ $\mathrm{HCl}$ solution to get rid of any $\mathrm{CaCO}_{3}$ particles and then rinsed with deionized water. All processes were performed under atmospheric pressure, and the constant temperature of the solution is equal to $25^{\circ} \mathrm{C}$. Gas inflow to the reactor was equal to $2 \mathrm{~L} \mathrm{~min}{ }^{-1}$ and was maintained at a constant level by Mass Flow Controller GFC (Aalborg) calibrated on $\mathrm{CO}_{2}$. The reaction kinetics was controlled by disks revolution speed rate equal to 120 revolutions per minute (rpm). The carbonation process was stopped when whole solution was neutralized ( $\mathrm{pH} 7)$. Then, precipitated solids were collected by filtering through membrane filter (Durapore ${ }^{\circledR}-0.1 \mu \mathrm{m}$ ), dried in shelf dryer at $80{ }^{\circ} \mathrm{C}$ for $24 \mathrm{~h}$ and stored in a desiccator. The obtained nano-powders have only one, the most stable crystallographic form of calcite [12-15].

\section{Characterization techniques}

\section{ITC experiments}

ITC measurements were taken at $298.15 \mathrm{~K}$ on Isothermal Titration Calorimeter Nano ITC (TA Instruments, model 601001). The parameters of the titration (the number-31, volume $-8 \mu \mathrm{L}$ and length of time of injections) were input into the ITCRun program controlling data. Nano ITC Standard Volume systems included buret syringe of $250 \mu \mathrm{L}$ capacities. The aqueous solutions in the cell were stirred at $250 \mathrm{rpm}$. The integrated heat effects of each injection were corrected by subtraction of the corresponding integrated heat effects associated with titrant dilution and any temperature difference between titrant and titrate solutions. The experimental data obtained from the calorimetric titration were analyzed on the basis of independent site model (TA Instruments NanoAnalyzeTM Software, Getting Started Guide).

\section{pH measurements}

The $\mathrm{pH}$ changes during reaction were measured by the use of combined glass electrode (IJ-44 for sewage and ultrapure water, IONODE, Australia). The $\mathrm{pH}$ meter was coupled with PC, and the experimental data were collected every second for carbonation time adjustment. The electrode was calibrated before every experiment on three buffer solutions (from CHEMPUR, Poland; $\mathrm{pH}$ at $25{ }^{\circ} \mathrm{C}$ equal to: 7.0, 9.0 and 12.0).

\section{TG/DSC experiments}

Simultaneously, the thermogravimetric (TG) and differential scanning calorimetry (DSC) analyses of pure $\mathrm{CaCO}_{3}$ and $\mathrm{CaCO}_{3}$ covered with the antibiotics were carried out by the use of NETZSCH STA449 F5. This analysis allowed for determination of both the antibiotics mass concentration and its way of $\mathrm{CaCO}_{3}$ covering (chemisorption, physical adsorption and formation of mono- and multilayers). Nitrogen pure gas used in the experiments was taken directly from a bottle. Mass flow controllers (MFC) controlled purge and protective gases to maintain optimum control of the atmosphere around the sample. The constant inflow of the gas was equal $20 \mathrm{~mL} \mathrm{~min}^{-1}$. The samples were heated from $25{ }^{\circ} \mathrm{C}$ to $620^{\circ} \mathrm{C}$ with the speed equal to 10 degrees per minute.

\section{Results}

\section{Inclusion complexes}

Isothermal titration calorimetry experiments have been performed at $298.15 \mathrm{~K}$ for the nine, mentioned above, following systems:

1. $\alpha$-Cyclodextrin + ampicillin-sodium,

2. $\alpha$-Cyclodextrin + penicillin $\mathrm{G}$-sodium,

3. $\alpha$-Cyclodextrin + streptomycin sulfate,

4. $\beta$-Cyclodextrin + ampicillin-sodium,

5. $\beta$-Cyclodextrin + penicillin $\mathrm{G}$-sodium,

6. $\beta$-Cyclodextrin + streptomycin sulfate,

7. $\gamma$-Cyclodextrin + ampicillin-sodium,

8. $\gamma$-Cyclodextrin + penicillin G-sodium,

9. $\gamma$-Cyclodextrin + streptomycin sulfate.

To ensure the accuracy of the results, each ITC experiment was repeated five times with the difference between the obtained equilibrium constants in each measurement less than $3 \%$.

For systems formed by streptomycin sulfate and all ( $\alpha$-, $\beta-, \gamma$-)natural cyclodextrins, the heat detected was on the level of the method accuracy, so no complex formation has been noticed.

The obtained results of the ITC experiments for rest systems are given in Table 1 . Table 1 shows the equilibrium constants $(K)$ and the changes in enthalpy of complex formation $(\Delta H)$ calculated by the model of a single set of identical sites (ITC Tutorial Guide) for all the investigated inclusion complexes.

Looking at the results of an ITC experiment for all the investigated systems (Table 1), it is seen that independently of the kind of cyclodextrin and antibiotics the obtained equilibrium constants are similar (varied from 
Table 1 Equilibrium constants $(K)$, the change in enthalpy $(\Delta H)$, the change in Gibbs energy $(\Delta G)$ and the change in entropy $(\Delta S)$ of complex formation for all the investigated inclusion complexes at $298.15 \mathrm{~K}$

\begin{tabular}{lcccc}
\hline Compound & $K / \mathrm{L} \mathrm{mol}^{-1}$ & $\Delta H / \mathrm{kJ} \mathrm{mol}^{-1}$ & $\Delta G / \mathrm{kJ} \mathrm{mol}^{-1}$ & $\Delta S / \mathrm{J} \mathrm{mol}^{-1} \mathrm{~K}^{-1}$ \\
\hline Ampicillin-sodium & & & & \\
$\alpha$-Cyclodextrin & $1.400 \times 10^{3} \pm 100$ & $-0.51 \pm 0.01$ & $-17.96 \pm 0.35$ & $58.53 \pm 0.81$ \\
$\beta$-Cyclodextrin & $1.047 \times 10^{3} \pm 106$ & $-1.53 \pm 0.09$ & $-17.24 \pm 0.16$ & $62.89 \pm 0.54$ \\
$\gamma$-Cyclodextrin & $1.023 \times 10^{3} \pm 107$ & $-1.12 \pm 0.01$ & $-17.29 \pm 0.28$ & $53.89 \pm 0.87$ \\
Penicillin G-sodium & & & & \\
$\alpha$-Cyclodextrin & $1.025 \times 10^{3} \pm 100$ & $-0.25 \pm 0.01$ & $-17.19 \pm 0.17$ & $56.81 \pm 0.81$ \\
$\beta$-Cyclodextrin & $1.001 \times 10^{3} \pm 100$ & $-1.34 \pm 0.17$ & $-17.13 \pm 0.25$ & $52.94 \pm 0.27$ \\
$\gamma$-Cyclodextrin & $1.297 \times 10^{3} \pm 100$ & $-1.21 \pm 0.04$ & $-17.12 \pm 0.21$ & $53.37 \pm 0.71$ \\
\hline
\end{tabular}

about 1000 to $1400 \mathrm{~mol}^{-1}$ ). The changes in enthalpy of complex formation vary from cyclodextrin to cyclodextrin with the highest value, for both antibiotics, obtained for $\beta$-cyclodextrin. The change in enthalpy of $\gamma$-cyclodextrins is much higher than for $\alpha$-cyclodextrins (2-5 times), but smaller than those for $\beta$-cyclodextrins. The stoichiometry of complexes formed both by ampicillin-sodium and by penicillin $\mathrm{G}$-sodium with all the natural cyclodextrins (best curve fitting of the enthalpy of complex formation) is the same and equal to $1: 1$. It confirms the calorimetric results ( $K$ and $\Delta H$ ) and shows, for the all complexes, on the similar interaction between different cyclodextrins and different antibiotics.

Based on the values of equilibrium constant $(K)$ and enthalpy of complex formation $(\Delta H)$, the Gibbs energy of complex formation $(\Delta G)$ and the entropy of complex formation $(\Delta S)$ have been calculated, for all the investigated systems, from the following equations:

$\ln K=-\frac{\Delta G}{R T}$

$\Delta G=\Delta H-T \Delta S$

where $T$-temperature $(\mathrm{K}), R$-gas constant $\left(\mathrm{J} \mathrm{mol}^{-1} \mathrm{~K}^{-1}\right)$.

The calculated values of the Gibbs energy and the entropy of complex formation for the all investigated systems are given in Table 1.

Results displayed in Table 1 clearly show that complex formation of all the investigated natural cyclodextrins with the all investigated antibiotics (ampicillin-sodium, penicillin $\mathrm{G}$-sodium) is entropy driven. This indicates that the difference in the cavity dimensions is not reflecting in different driving forces of complex formation and binding modes what results in the same stoichiometry of the obtained inclusion complexes. It is necessary to point out also the positive change of entropy of the obtained complexes caused by the brakeage of hydration shells and release of water molecules to the bulk.

It is worth mentioning also that the difference in cyclodextrin cavity has no influence on the stoichiometry of the complex formed. Both the antibiotics have similar size, small enough to form inclusion complex with $\alpha$-cyclodextrin with the stoichiometry $1: 1$. That is why wider cavity of $\beta$ - and $\gamma$-cyclodextrin makes even easier formation of 1:1 complexes with those cyclodextrins. Moreover, results presented in Table 1 show that the highest entropy contribution is seen for complexes formed with $\alpha$-cyclodextrin what confirms the above conclusion.

Looking at the obtained results (Table 1), it is seen the similar way of complexation for the all complexes formed. It means that in these cases we deal with similar van der Waals interaction between cyclodextrins and antibiotics what can be explained by the similar size, shape and mass of the investigated antibiotic particles. The obtained results fully agree with the results obtained by Aki et al. [45] $\left(\Delta H=-1.67 \pm 0.4 \mathrm{~kJ} \mathrm{~mol}^{-1}, \Delta G=-17.5 \mathrm{~kJ} \mathrm{~mol}^{-1}\right)$ who investigated, by the use of calorimetric titration and NMR method, formation of inclusion complexes for ampicillin with $\beta$-cyclodextrin. Their results show that the complexation was entropy driven to reflect hydrophobic interactions and the complex stoichiometry was equal to $1: 1$.

\section{Adsorption}

The nano-metric calcium carbonate obtained in the reactor with rotating disks (RDR) [12-15], after drying for $2 \mathrm{~h}$, at $400{ }^{\circ} \mathrm{C}$ in an electric oven, was used as a carrier for all the investigated drugs. The first series of experiments concerning adsorption of antibiotics on nano-metric $\mathrm{CaCO}_{3}$ were performed for the amount of drugs corresponding to the theoretically calculated concentration needed for covering of whole $\mathrm{CaCO}_{3}$ surface with a monolayer. In this series, an antibiotic was shaken with nano-calcite into $10 \mathrm{~mL}$ of distillated water for $24 \mathrm{~h}$. In the second series of experiments, 10 times higher amount of antibiotic was shaken with nanometric $\mathrm{CaCO}_{3}$ into $10 \mathrm{~mL}$ of distillated water for $168 \mathrm{~h}$. The detailed information concerning the amounts of antibiotics and nano-metric $\mathrm{CaCO}_{3}$ used in those experiments is summarized in Table 2.

After shaking the samples, they were filtered through a filter having a pore size $200 \mathrm{~nm}$, dried at $353.15 \mathrm{~K}$ and 
Table 2 Amounts of antibiotics and nano-metric $\mathrm{CaCO}_{3}$ used in the experiments and for preparation of the physical mixtures together with the amounts of antibiotics adsorbed on nano-calcite surface

\begin{tabular}{lcccc}
\hline & Time & $\begin{array}{l}\text { Ampicillin- } \\
\text { sodium }\end{array}$ & $\begin{array}{l}\text { Penicillin } \mathrm{G}- \\
\text { sodium }\end{array}$ & $\begin{array}{l}\text { Streptomy- } \\
\text { cin sulfate }\end{array}$ \\
\hline Antibiotics and nano-metric $\mathrm{CaCO}_{3}$ used in the experiments & $24 \mathrm{~h}$ & 2.8 & 3.1 & 2.4 \\
Mass of antibiotic/mg & $168 \mathrm{~h}$ & 29.9 & 29.9 & 24.8 \\
& $24 \mathrm{~h}$ & 50.7 & 49.9 & 50.6 \\
Mass of nano-metric $\mathrm{CaCO}_{3} / \mathrm{mg}$ & $168 \mathrm{~h}$ & 50.8 & 50.7 & 50.3 \\
& & & & \\
Physical mixture & & 8.8 & 9.0 & 12.2 \\
Mass of antibiotic/mg & 91.2 & 91.0 & 87.8 \\
Mass of nano-metric $\mathrm{CaCO}_{3} / \mathrm{mg}$ & & & & \\
Antibiotics adsorbed on nano-calcite surface & $24 \mathrm{~h}$ & 0.98 & 0.61 & 0.88 \\
The amounts of antibiotic/mg & $168 \mathrm{~h}$ & 1.47 & 0.81 & 0.91 \\
\end{tabular}

stored in an vacuum (0.05 $\mathrm{MPa})$ dryer. Prepared in such a way, powders were further used for TG/DSC analysis in the temperature range $40-600{ }^{\circ} \mathrm{C}$. Results of the analysis are shown in Figs. 1-3.

Because thermogravimetric analysis cannot give an unequivocally answer concerning a substance which mass lost is observed we used also the differential scanning calorimetry. DSC traces obtained for the investigated samples (Figs. 1, 3) show a sudden change of slope between 240 and $290{ }^{\circ} \mathrm{C}$ which is connected with a phase transition. It is necessary to point out that in these cases instead of the separate peaks of melting and adsorption we see one peak moved to the higher temperatures. The biggest change was observed for ampicillin sodium (Figs. 1, 3). Pure ampicillin sodium melts at $241{ }^{\circ} \mathrm{C}$. At the ampicillin sodium DSC trace (Fig. 3), a change of slope appears at ca. $280{ }^{\circ} \mathrm{C}$ what suggests that we deal with an adsorption of ampicillin sodium on the nanometric $\mathrm{CaCO}_{3}$.

Looking at all the DSC traces (Figs. 1, 3), it is seen that longer shaking causes better adsorption of antibiotics on the nano-calcite. The amount of the adsorbed antibiotics was determined by thermogravimetric analysis (Fig. 2). To have the possibility of distinction between amount of antibiotics adsorbed on the nano-metric $\mathrm{CaCO}_{3}$ surface and mixed

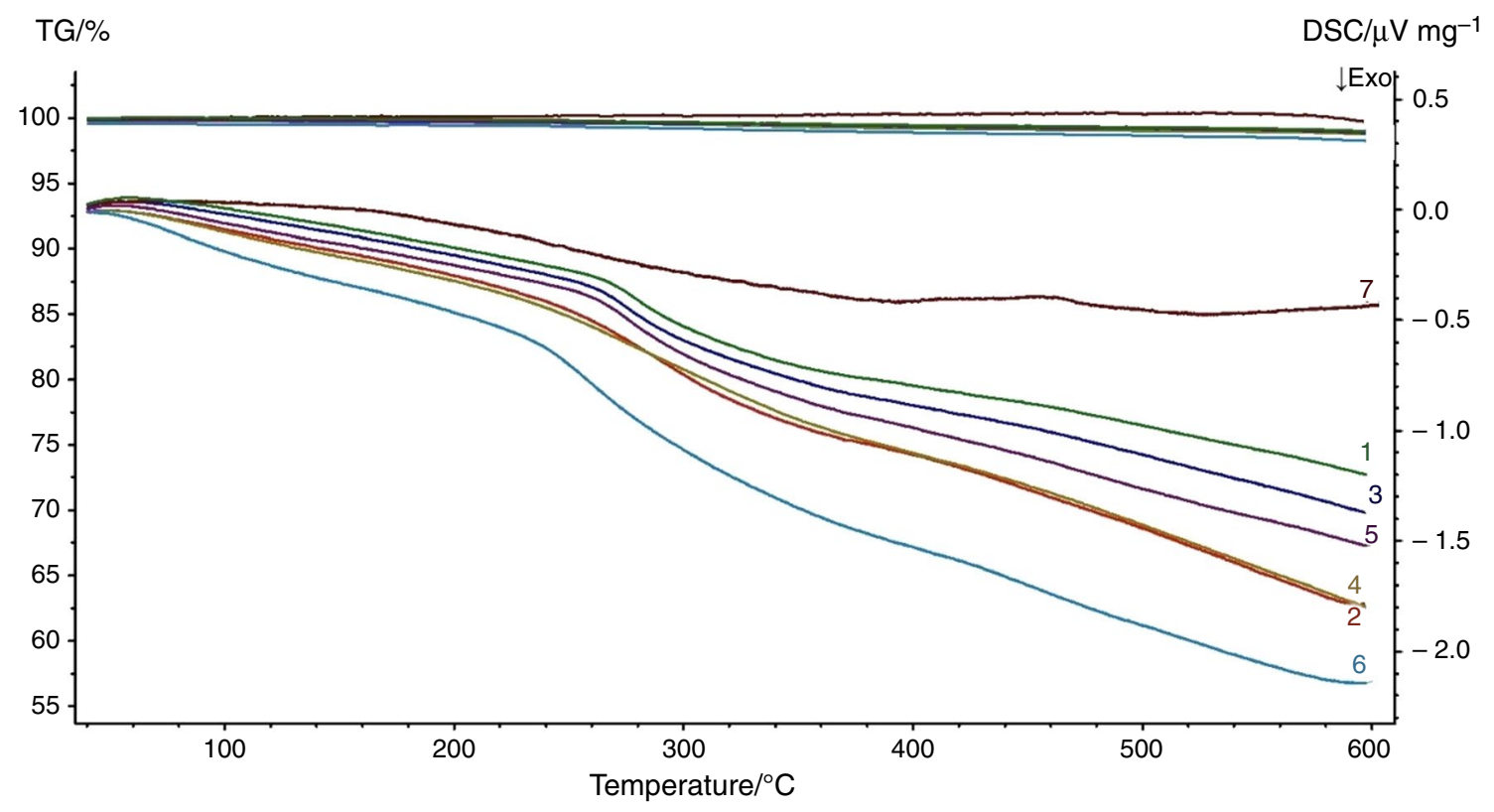

Fig. 1 Results of TG/DSC analysis obtained for adsorption: (1) ampicillin sodium-after $24 \mathrm{~h}$ shaking the sample; (2) penicillin G sodium-after $168 \mathrm{~h}$ shaking the sample; (3) penicillin G sodiumafter $24 \mathrm{~h}$ shaking the sample; (4) streptomycin sulfate-after $168 \mathrm{~h}$ shaking the sample; (5) streptomycin sulfate-after $24 \mathrm{~h}$ shaking the sample; (6) ampicillin sodium-after $168 \mathrm{~h}$ shaking the sample; (7) pure nano-calcite 


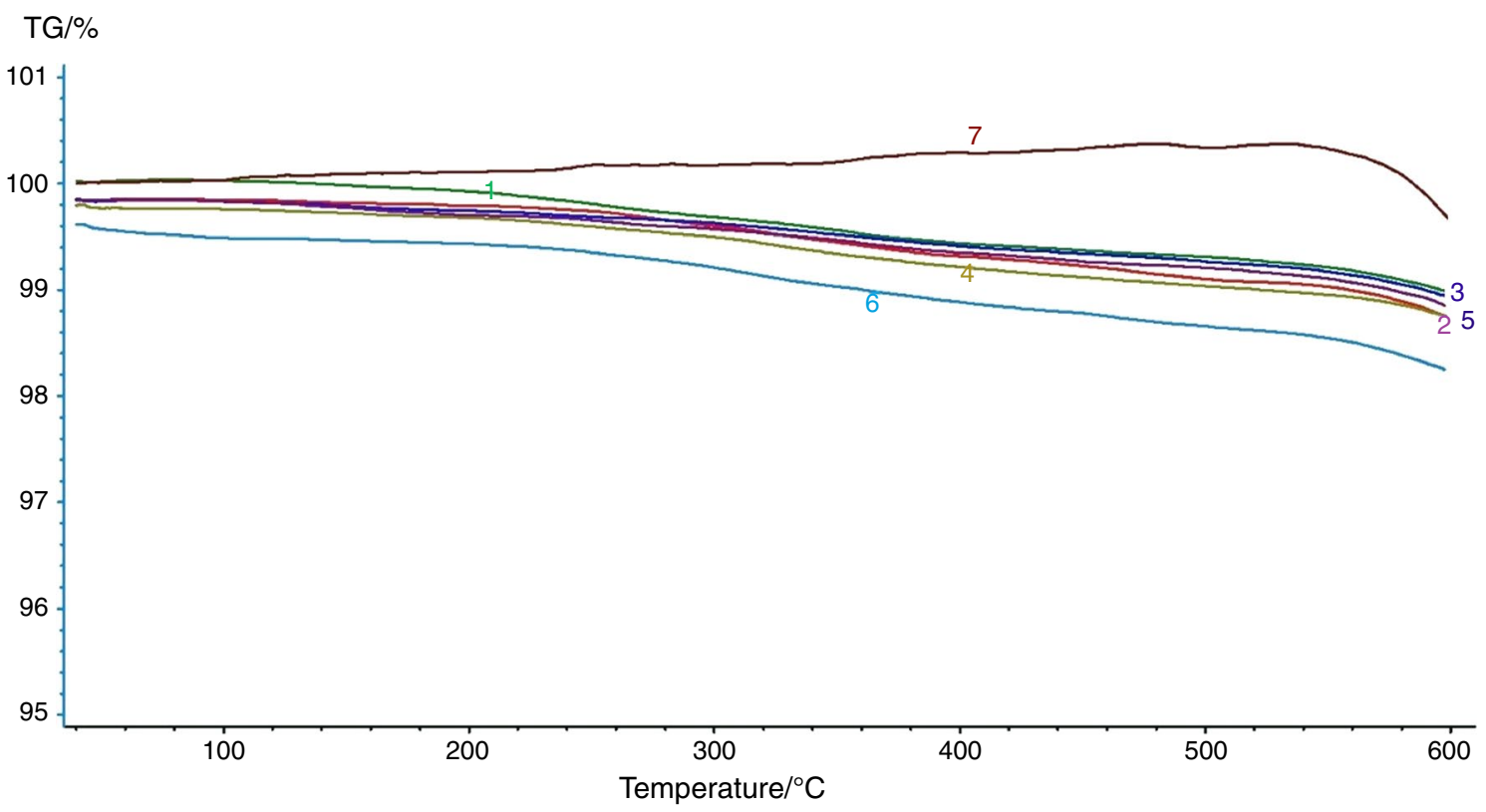

Fig. 2 Results of TG analysis obtained for adsorption: (1) ampicillin sodium-after $24 \mathrm{~h}$ shaking the sample; (2) penicillin G sodiumafter $168 \mathrm{~h}$ shaking the sample; (3) penicillin G sodium-after $24 \mathrm{~h}$ shaking the sample; (4) streptomycin sulfate—after $168 \mathrm{~h}$ shaking the sample; (5) streptomycin sulfate-after $24 \mathrm{~h}$ shaking the sample; (6) ampicillin sodium-after $168 \mathrm{~h}$ shaking the sample; (7) pure nanocalcite

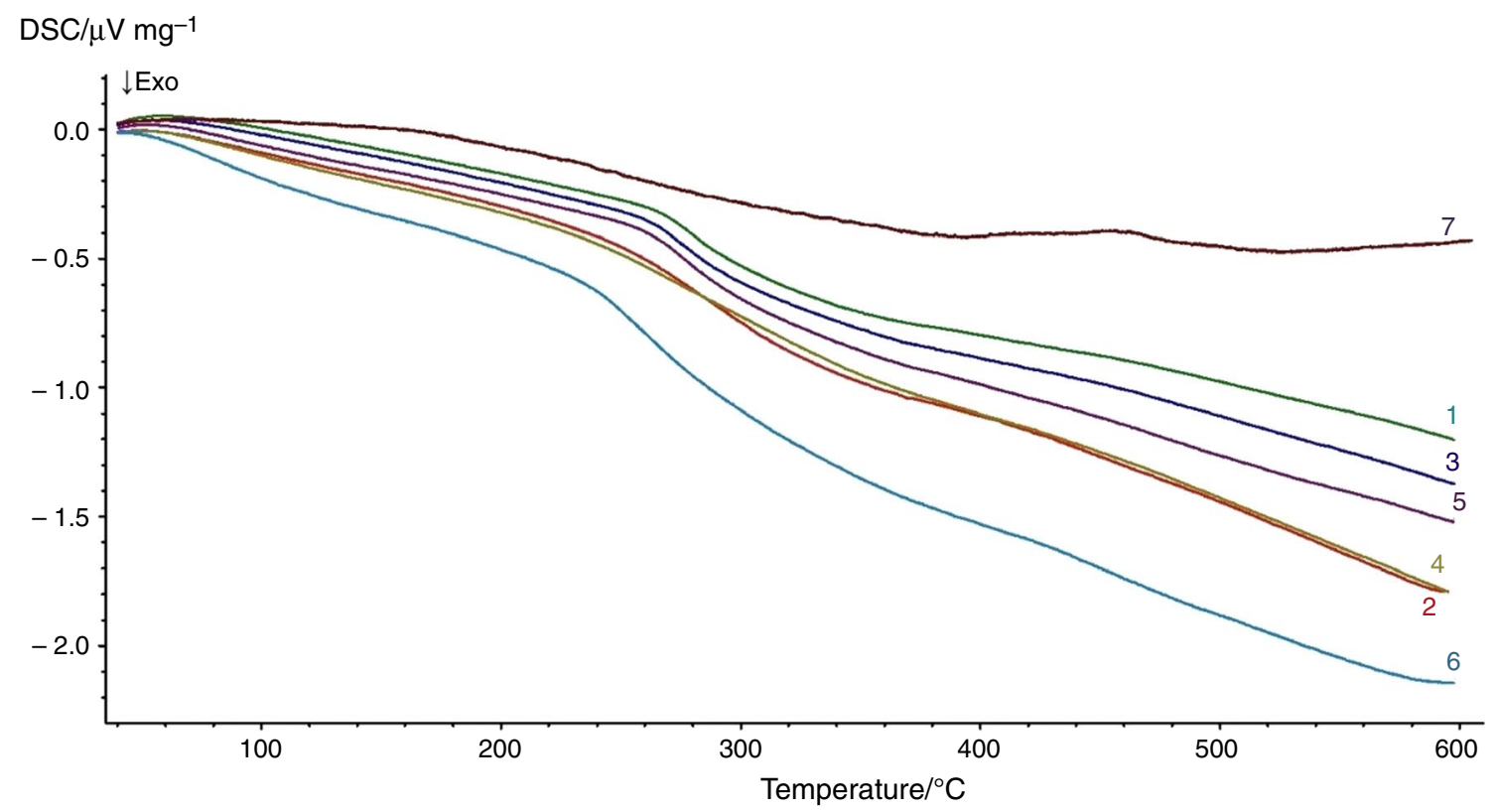

Fig. 3 Results of DSC analysis obtained for adsorption: (1) ampicillin sodium-after $24 \mathrm{~h}$ shaking the sample; (2) penicillin G sodiumafter $168 \mathrm{~h}$ shaking the sample; (3) penicillin G sodium-after $24 \mathrm{~h}$ shaking the sample; (4) streptomycin sulfate-after $168 \mathrm{~h}$ shaking the sample; (5) streptomycin sulfate-after 24 h shaking the sample; (6) ampicillin sodium-after $168 \mathrm{~h}$ shaking the sample; (7) pure nanocalcite 


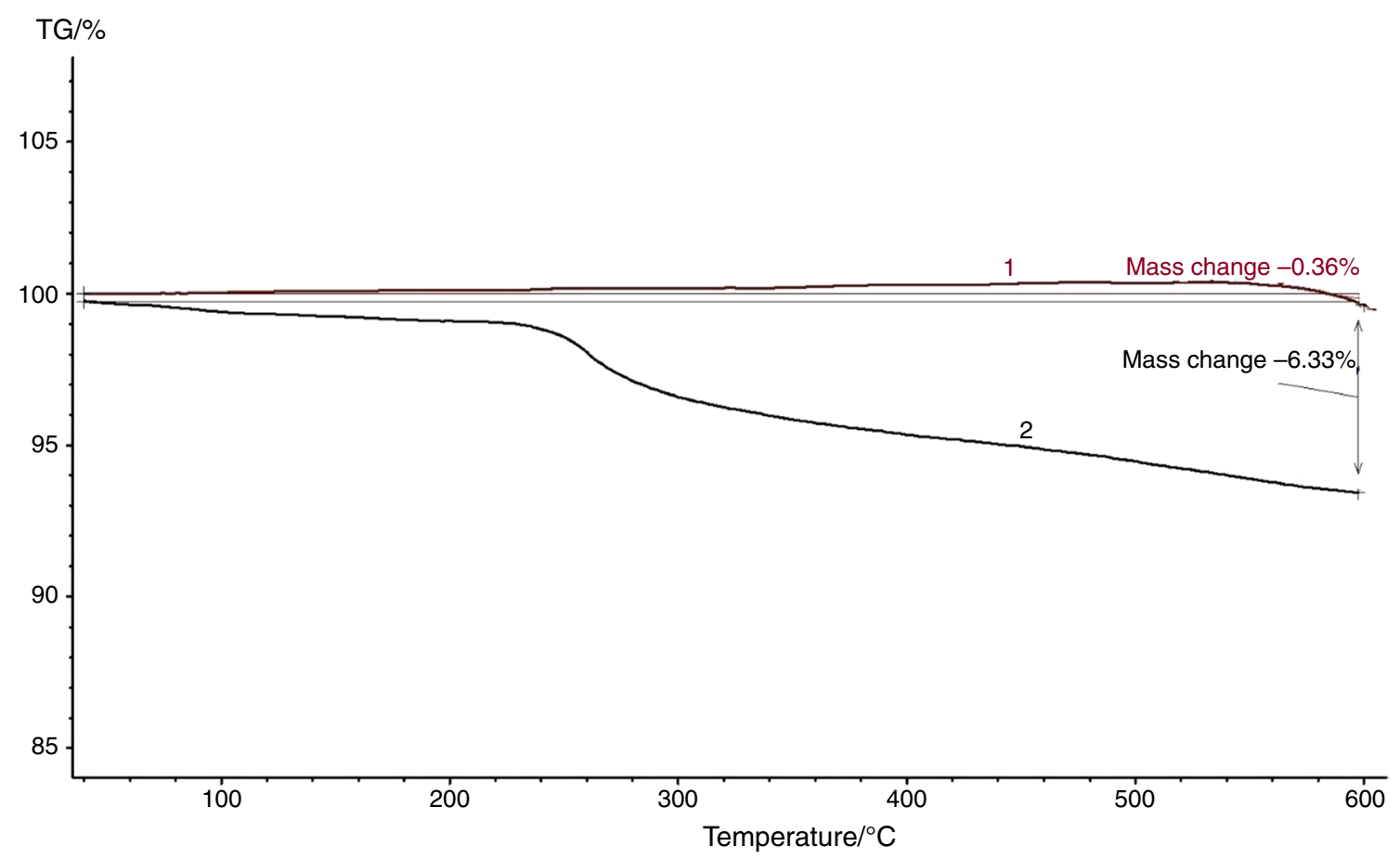

Fig. 4 Results of TG analysis for physical mixtures of pure nano-calcite and ampicillin sodium: (1) pure calcite; (2) physical mixtures of pure nano-calcite and ampicillin sodium

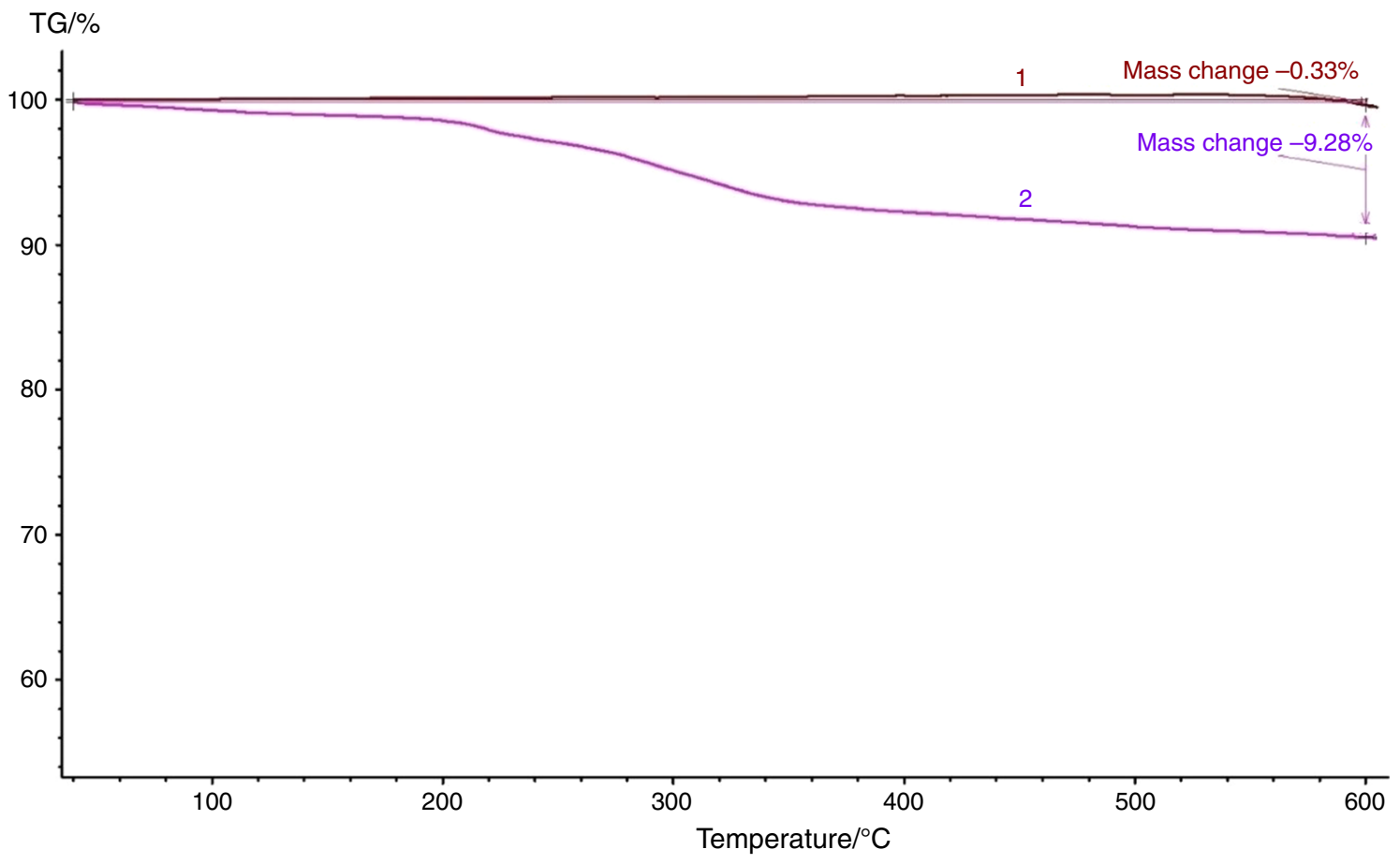

Fig. 5 Results of TG analysis for physical mixtures of pure nano-calcite and streptomycin sulfate: (1) pure calcite; (2) physical mixtures of pure nano-calcite and streptomycin sulfate 


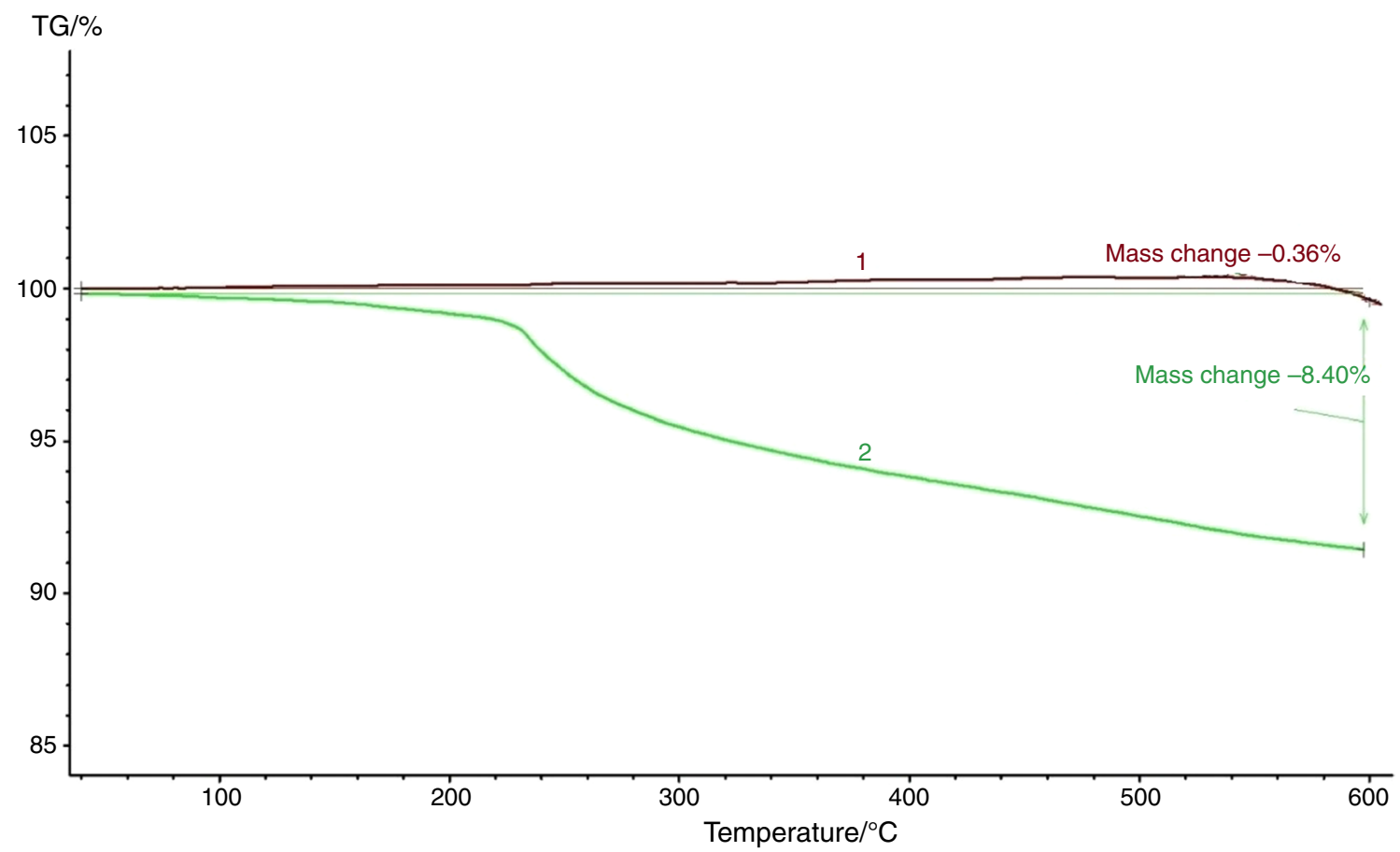

Fig. 6 Results of TG analysis for physical mixtures of pure nano-calcite and penicillin G sodium: (1) pure calcite; (2) physical mixture of pure nano-calcite and penicillin $\mathrm{G}$

with nano-calcite, the physical mixtures of all antibiotics with nano-metric $\mathrm{CaCO}_{3}$ were prepared and analyzed by the use of TG method. The detailed information concerning composition of the physical mixture is given in Table 2, and the obtained TG traces are shown in Figs. 4-6.

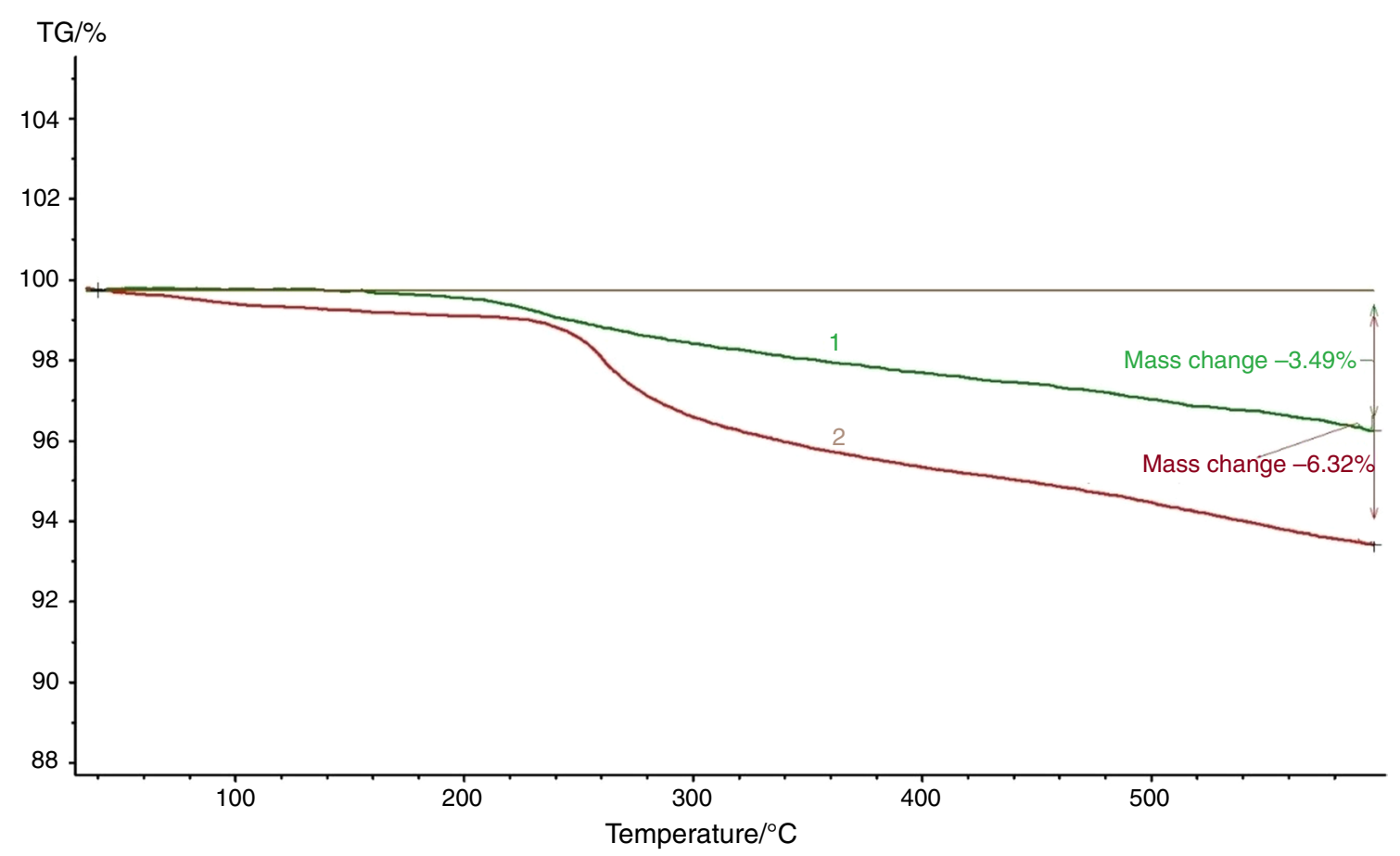

Fig. 7 Results of TG analysis for intercalation of ampicillin—sodium into the nano-calcite structure: (1) pure calcite, (2) calcite with intercalated ampicillin—sodium 


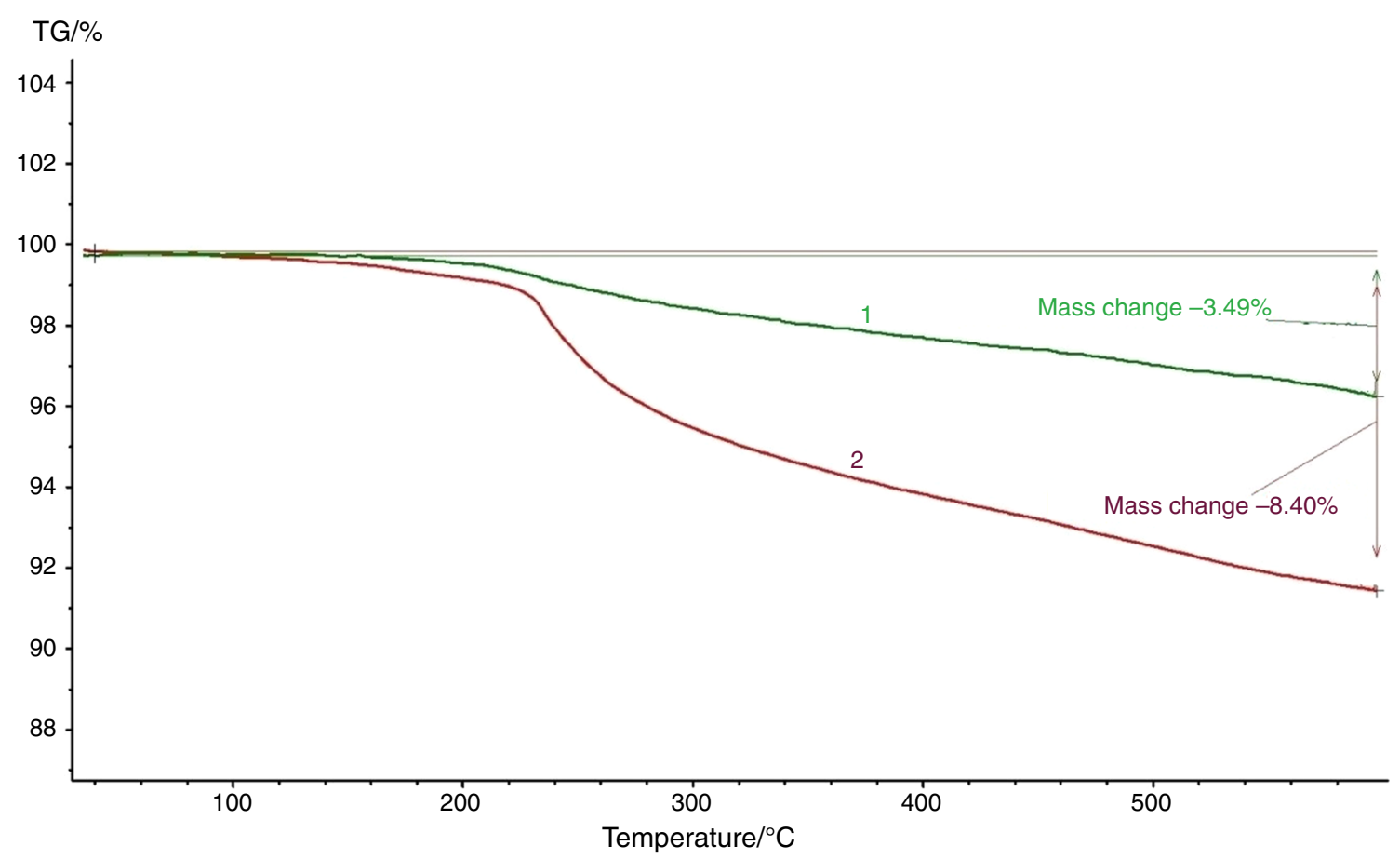

Fig. 8 Results of TG analysis for intercalation of penicillin G-sodium into the nano-calcite structure: (1) pure calcite, (2) calcite with intercalated penicillin $\mathrm{G}$-sodium

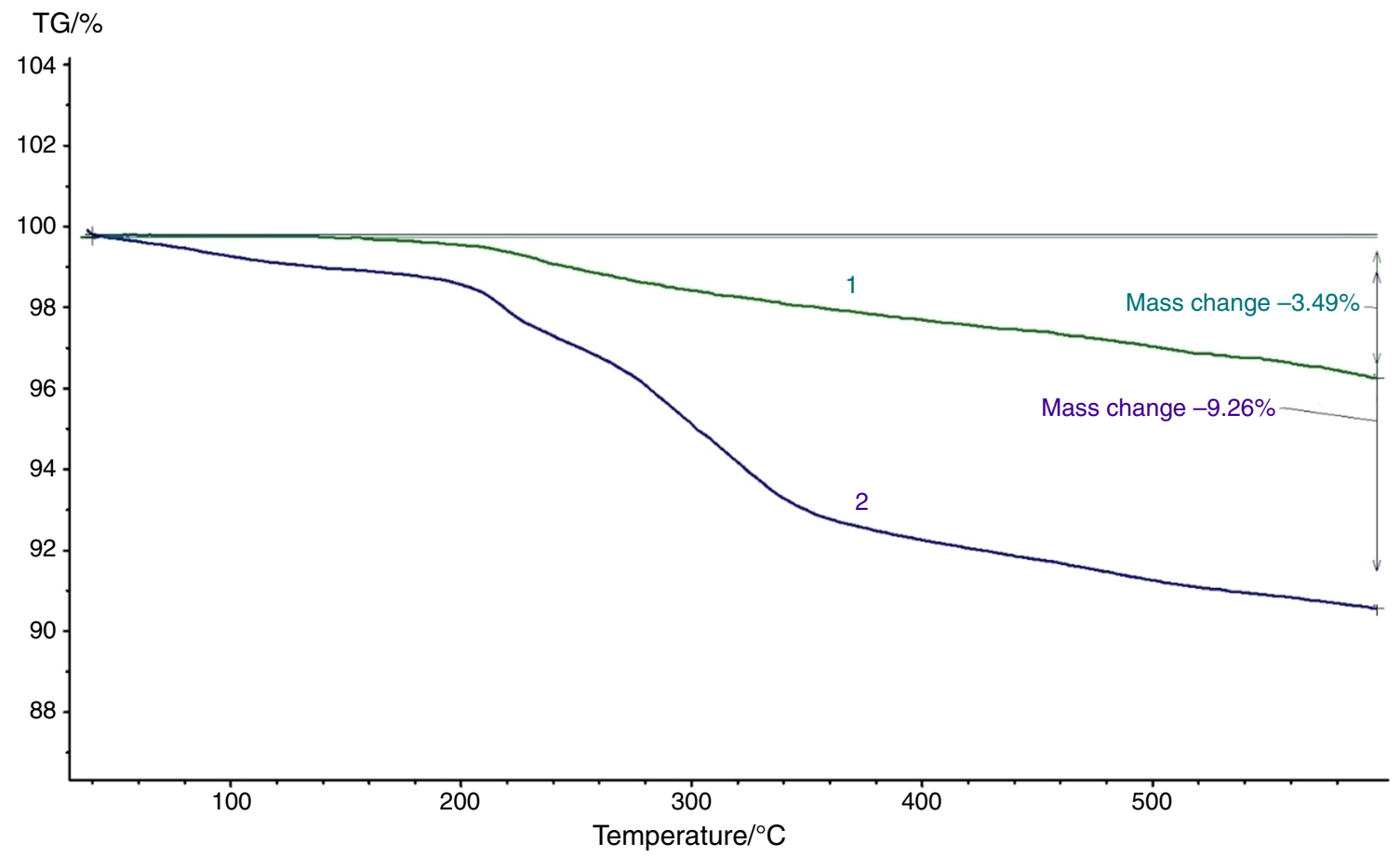

Fig. 9 Results of TG analysis for intercalation of streptomycin sulfate into the nano-calcite structure: (1) pure calcite, (2) calcite with intercalated streptomycin sulfate 
Table 3 Amounts of antibiotics intercalated into the nano-calcite structure

\begin{tabular}{ll}
\hline Name & $\begin{array}{l}\text { The amounts } \\
\text { of antibi- } \\
\text { otic/\% }\end{array}$ \\
\hline Ampicillin_sodium & 2.83 \\
Penicillin G-sodium & 4.91 \\
Streptomycin sulfate & 5.77 \\
\hline
\end{tabular}

Based on the information obtained from TG analysis done for physical mixtures of antibiotics with nano-calcite (Figs. 4-6), the amount of absorbed antibiotics on the nanometric $\mathrm{CaCO}_{3}$ surface could be determined from TG analysis presented in Fig. 2. The detailed information concerning amount of the antibiotics adsorbed on nano-calcite surface is given in Table 2. The obtained results show that we deal with much more effective adsorption of the antibiotics on the nano-metric calcite when we shake $\mathrm{CaCO}_{3}$ nano-crystals with 10 times higher amount of drugs than that needed for covering of whole $\mathrm{CaCO}_{3}$ surface with a monolayer for a long time $(168 \mathrm{~h})$. In both series of experiments ( 24 and $168 \mathrm{~h}$ ), streptomycin sulfate was adsorbed in the lower amount. The adsorption of the left two antibiotics (ampicillin-sodium and penicillin G-sodium) was on the same level.

The performed investigations show that adsorption of pure antibiotics on the surface of nano-metric calcium carbonate obtained in the reactor with rotating disks (RDR)
[12-15] is possible and depends on the both amount of antibiotic used and time of its shaking with nano-calcite.

It is necessary to point out the difference between covering on nano- $\mathrm{CaCO}_{3}$ with inclusion complexes of natural cyclodextrins with investigated antibiotics and adsorption of those antibiotics on nano-metric $\mathrm{CaCO}_{3}$. It the first case, we deal with the formation of complexes of stoichiometry 1:1. It means one natural cyclodextrin particle on one antibiotic particle. Such complex particle has much higher surface than the surface of pure antibiotic. It means that if we covered the nano-metric $\mathrm{CaCO}_{3}$ with such complex the amount of pure antibiotics on the carrier would be much smaller than in the case of covering it by pure antibiotic. Moreover, the obtained results show that in the case of long shaking the amount of adsorbed antibiotics on $\mathrm{CaCO}_{3}$ increases significantly. That is why adsorption of pure antibiotics on the surface of nanometric $\mathrm{CaCO}_{3}$ seems to be more effective that adsorption of their natural cyclodextrin inclusion complexes.

\section{Intercalation}

The second group of experiments was concerned with intercalation of antibiotics in the aggregates of nano-metric calcium carbonate. The obtained in the reactor with rotating disks (RDR) nano-crystals $\mathrm{CaCO}_{3}[12-15]$ aggregate during and after the reaction [12]. Therefore, we performed two series of investigations. In the first series, the antibiotics were added to the reactor chamber at the beginning of the reaction and in the second after the end of reaction. Obtained in such a way, nano-powders with intercalated antibiotics

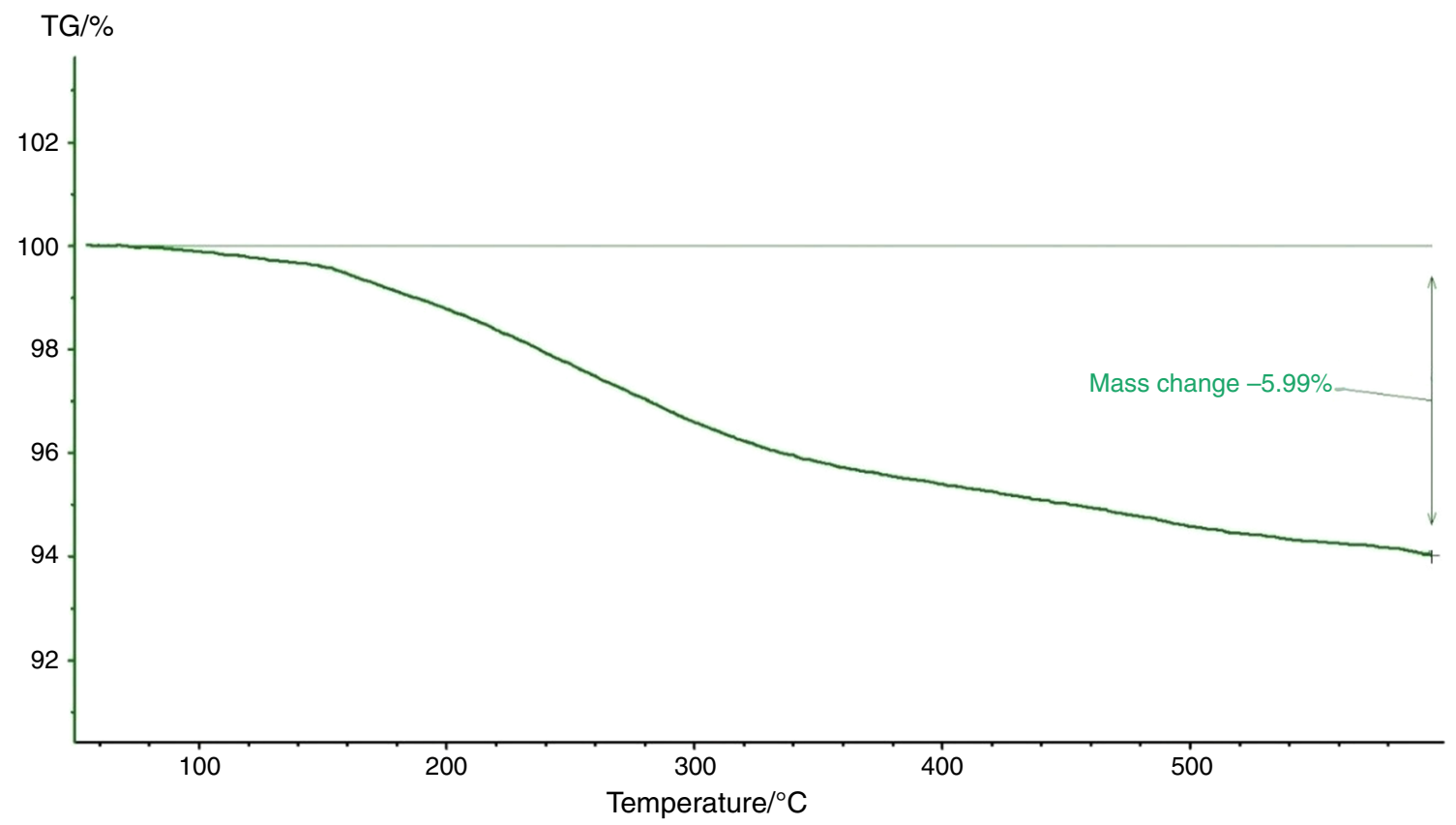

Fig. 10 Results of TG analysis for intercalation of ampicillin—sodium into the nano-calcite (second series of experiments) 


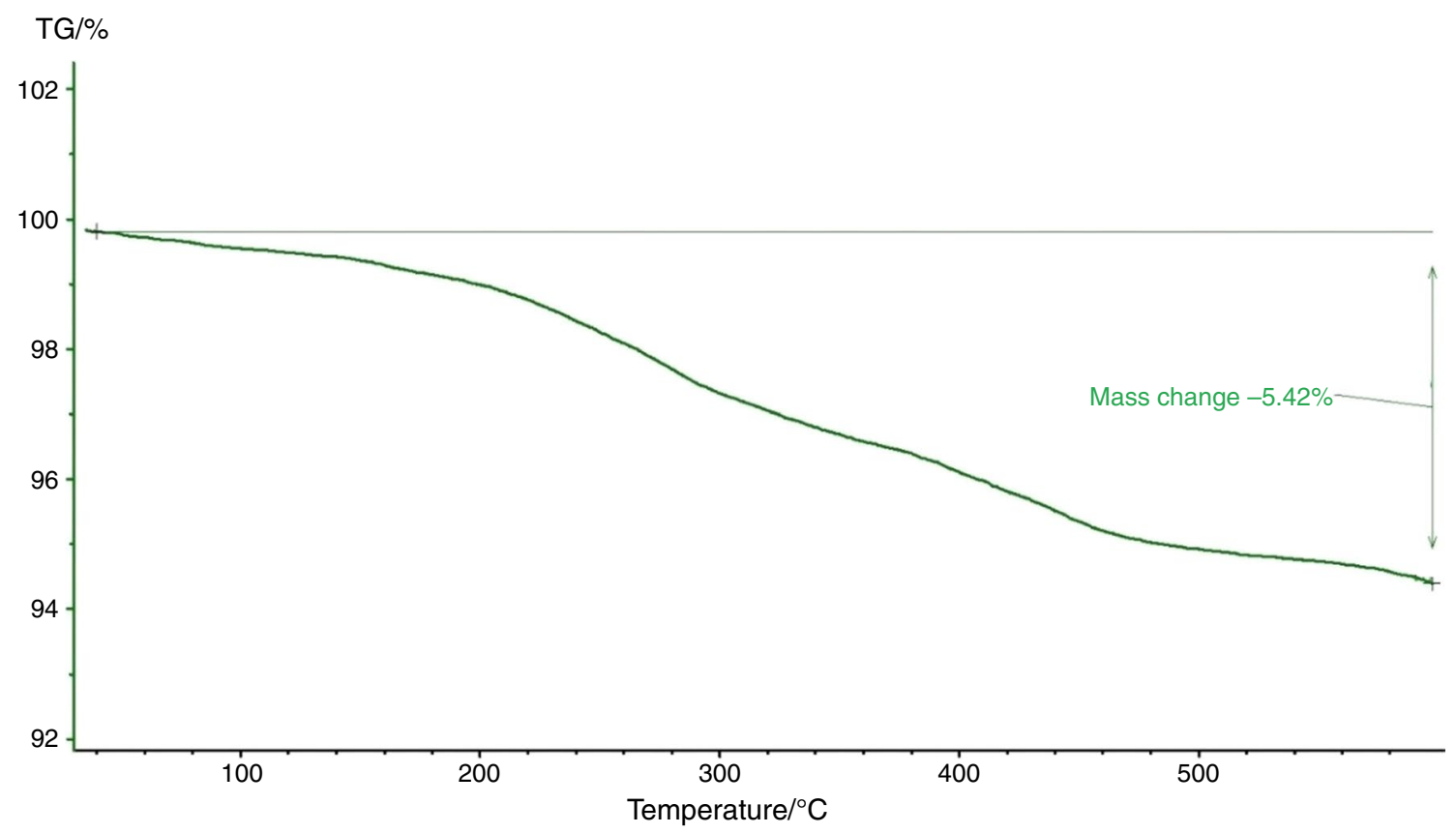

Fig. 11 Results of TG analysis for intercalation of penicillin G-sodium into the nano-calcite (second series of experiments)

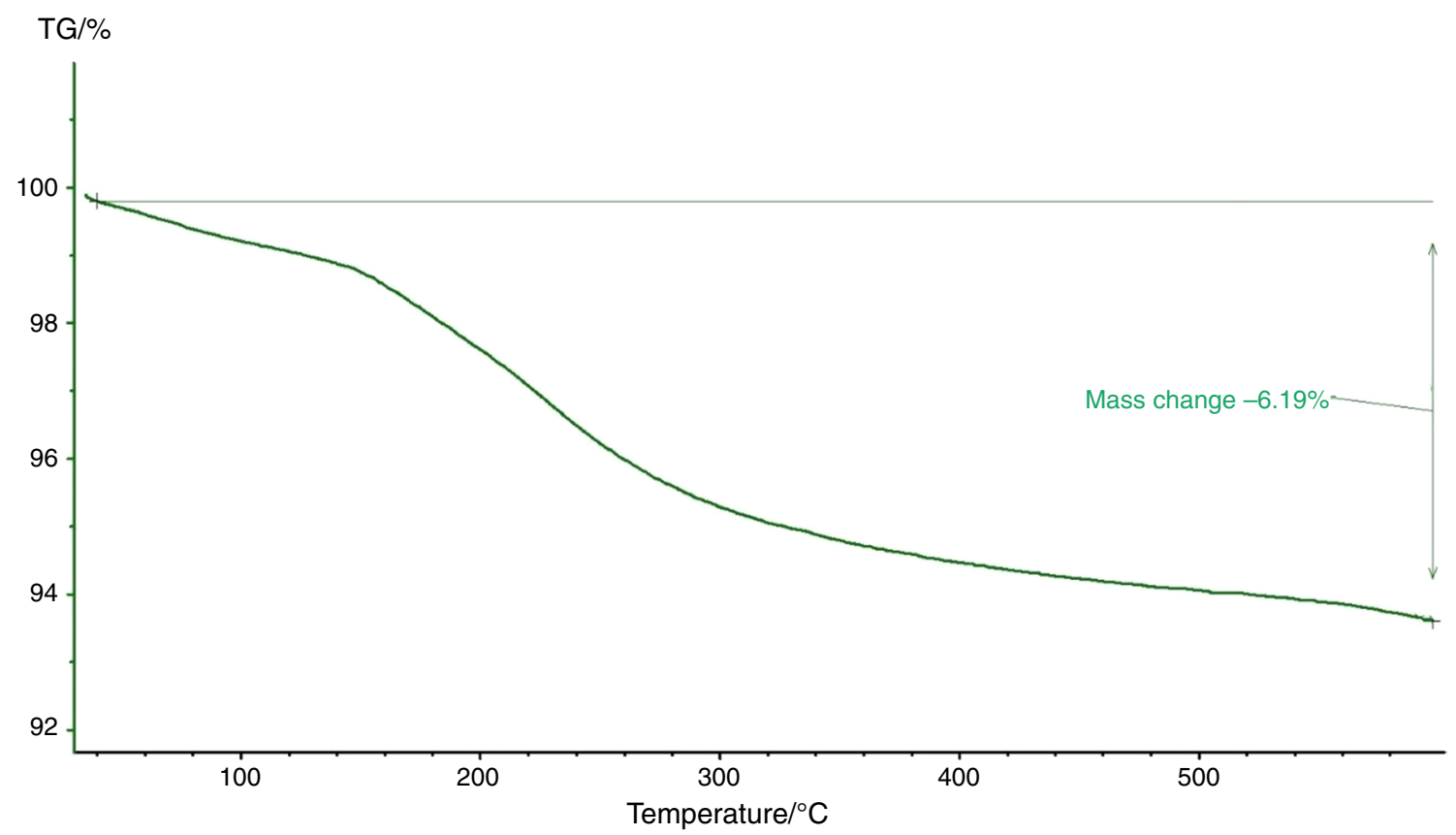

Fig. 12 Results of TG analysis for intercalation of streptomycin sulfate into the nano-calcite (second series of experiments)

were analyzed by the use of TG/DSC method. In the first series of experiments, the amount of antibiotics added to the reactor chamber was evaluated according to Ueno et al. [20] procedure. In our case, in the RDR during one experiment we produce $4.69 \mathrm{~g}$ of nano-metric $\mathrm{CaCO}_{3}[13,14]$. According to Ueno et al. [20] for such amount of nano-calcite, we should add to the reactor chamber ca. $0.666 \mathrm{~mol}$ of each antibiotics. Therefore, we added $0.500 \mathrm{~g}$ of streptomycin sulfate, $0.250 \mathrm{~g}$ of ampicillin-sodium and $0.25 \mathrm{~g}$ of penicillin G-sodium. After the end of the reaction, 11 of the product was collected, filtered and dried. Then the samples were analyzed by the use of TG method. 
Table 4 Amounts of antibiotics intercalated into the nano-calcite structure (second series of the experiments)

\begin{tabular}{ll}
\hline Name & $\begin{array}{l}\text { The amounts } \\
\text { of antibi- } \\
\text { otic/\% }\end{array}$ \\
\hline Ampicillin—sodium & 5.99 \\
Penicillin G-sodium & 5.42 \\
Streptomycin sulfate & 6.19 \\
\hline
\end{tabular}

The obtained results (TG traces) for all the investigated antibiotics (ampicillin—sodium, penicillin G-sodium, streptomycin sulfate) are given in Figs. 7-9 and Table 3.

It is necessary to notice (Figs. 7-9) that calcite obtained directly in the reactor contains some impurities which disappeared after its heating (up to $400{ }^{\circ} \mathrm{C}$ ) in the electric oven (Figs. 2, 4-6). Anyway it is seen (Table 2) that the amount of antibiotics intercalated in the nano-calcite structure is much higher (2-6 times) than the amount of antibiotics adsorbed on nano-calcite surface. The highest intercalated amount of antibiotic was obtained for streptomycin sulfate and penicillin G-sodium. It can be caused by the structure of the antibiotics because it is known $[20,21]$ that their incorporation into nano-metric $\mathrm{CaCO}_{3}$ is related to their hydrophilicity (the higher hydrophilicity the better incorporation). The structure of streptomycin sulfate significantly (much higher number of $-\mathrm{H}$ atoms) differs from two other antibiotics; therefore, its higher incorporation into nano-calcite structure could be expected. In the case of penicillin G-sodium and ampicillin-sodium, we deal with a different situation. Both drugs have very similar structure (a difference in one $-\mathrm{H}$ atom); that is why one could expect that they incorporation into nano-calcite should be also similar. However, the experimental results (Table 3) are opposite. It can be explained by influence of the antibiotics on formation of nano-metric $\mathrm{CaCO}_{3}$ aggregates. The adsorption and the intercalation of biomacromolecules into porous nano-metric calcium carbonate particles can be presumably regulated by electrostatic interactions on the aggregates surface and pores [22, 23], or the addition of antibiotic at the beginning of the reaction may cause a formation of short-lived $\mathrm{Ca}^{2+}$-antibiotic complex which influences the crystal growth of $\mathrm{CaCO}_{3}$ [20-28].

The different interaction between ampicillin - sodium and nano-calcite compared to the interaction between penicillin G-sodium and streptomycin sulfate with nano-calcite was confirmed by the experiments concerning adsorption of antibiotics on the nano-metric $\mathrm{CaCO}_{3}$ (Figs. 1-6, Table 2). In this situation, the obtained results were opposite to the intercalation results. The highest amount (almost 2 times) of adsorbed drugs was obtained for ampicillin-sodium (Table 2). The two other drugs (penicillin G-sodium and streptomycin sulfate) were adsorbed (Table 2) in the similar way, but worse than ampicillin-sodium. However, in the case of both adsorption (Table 2) and intercalation (Table 3) the difference in behavior of ampicillin-sodium and two left antibiotics is clearly seen.

The second, last, series of experiments was concerned with intercalation of the antibiotics into nano-calcite aggregates structure after the end of reaction performed in the RDR [12-15]. In these investigations, $0.500 \mathrm{~g}$ of each antibiotic was added, just after the end of the reaction, to the $25 \mathrm{~mL}$ of nano-metric $\mathrm{CaCO}_{3}$ suspension obtained in the RDR. The samples were mixed for $24 \mathrm{~h}$, dried and analyzed by the TG method. The obtained results for all the investigated antibiotics are given in Figs. 10-12 and Table 4.

The obtained results (Table 4 and Figs. 10-12) show that in this case the amount of intercalated drugs into the nanocalcite structure for the all antibiotics investigated is very similar and not dependent (or only slightly dependent) on the structure of the antibiotic used. Moreover, in this series the amount of intercalated antibiotics into the nano-calcite structure was the highest from the all three performed investigations (Table 2, 3, 4). Comparing the results obtained for intercalation of antibiotics (Figs. 10-12) to the results of TG analysis for physical mixtures of the antibiotics with pure nano-calcite (Figs. 4-6), it is clearly seen that in this case we deal only with intercalated antibiotics into nanocalcite structure without additional adsorption. (The mass lost in both cases is in the same temperature range.) The results confirm also our hypothesis concerning the interaction between the antibiotics and $\mathrm{Ca}^{2+}$ ions during the reaction taking place in the RDR (Table 2). In the case of intercalation of the antibiotics after the reaction (Table 4), we deal more with encapsulation that interaction of the used drugs with nano-metric $\mathrm{CaCO}_{3}$ what agrees with the results obtained by Wang et al. [22] and Sukhorukov et al. [23].

\section{Conclusions}

The analysis of investigation results of the inclusion complexes shows that independently of the kind of cyclodextrin and antibiotics the obtained equilibrium constants are almost the same, what means that for the all complexes we deal with similar interaction between different cyclodextrins and different antibiotics. However, it is a difference between the enthalpies of complex formation for the investigated systems. The strongest inclusion complexes (highest $\Delta H$ ), for both antibiotics, are formed for $\beta$-cyclodextrin systems.

The stoichiometry of complexes formed both by ampicillin — sodium and by penicillin G-sodium with all the natural cyclodextrins is the same and equal to $1: 1$, and the complex formation is entropy driven.

The performed investigations showed also that all the antibiotics used (ampicillin sodium, penicillin G-sodium and streptomycin sulfate) can be both adsorbed and intercalated 
into the nano-metric $\mathrm{CaCO}_{3}$ obtained in the reactor with rotating disks. The highest amount of all antibiotics in the structure of nano-calcite was obtained for the use of intercalation method in which the antibiotics were added to the nano-metric $\mathrm{CaCO}_{3}$ samples taken just after the end of the precipitation reaction. Moreover, in this case the amount of intercalated drugs into the nano-calcite structure for the all antibiotics investigated was very similar and not dependent on the structure of the antibiotic used. The lowest amount of all antibiotics in the structure of nano-calcite was obtained for the use of adsorption method. In this case, the difference in the amount of adsorbed antibiotics on the nano-metric $\mathrm{CaCO}_{3}$ was seen. The highest amount (almost 2 times) of adsorbed drugs was obtained for ampicillin—sodium. The two other drugs (penicillin G-sodium and streptomycin sulfate) were adsorbed in the similar way (adsorption on the same level), but worse than ampicillin-sodium. The different adsorption obtained by different antibiotics was caused by the different interaction between them and nano-calcite, caused by their different structure.

Similar interaction between penicillin G-sodium with nano-calcite and streptomycin sulfate with nano-calcite was confirmed also by the use of the intercalation method where the antibiotics were added at the beginning of the precipitation reaction. In both cases, the similar amount of antibiotic (higher than that for adsorption method, but lower than that for intercalation method in which the antibiotics were added at the end of reaction) was intercalated into nano-metric $\mathrm{CaCO}_{3}$ structure. This amount was much higher than amount of ampicillin-sodium intercalated into nano-calcite structure. These results unequivocally show that in the case of both adsorption and intercalation we deal with the difference in interaction of ampicillinsodium and two left antibiotics with nano-metric $\mathrm{CaCO}_{3}$.

The conducted research shows that both approaches used for investigated antibiotics (ampicillin—sodium, penicillin G-sodium), i.e., formation of inclusion complexes with natural cyclodextrins and covering (adsorption and intercalation) of nano-metric $\mathrm{CaCO}_{3}$, can be successfully implemented for their pharmaceutical applications. The obtained results confirm the status of cyclodextrins as useful pharmaceutical excipients and known opinion that nano-metric $\mathrm{CaCO}_{3}$ can be used as a one of the best drug carriers.

Open Access This article is licensed under a Creative Commons Attribution 4.0 International License, which permits use, sharing, adaptation, distribution and reproduction in any medium or format, as long as you give appropriate credit to the original author(s) and the source, provide a link to the Creative Commons licence, and indicate if changes were made. The images or other third party material in this article are included in the article's Creative Commons licence, unless indicated otherwise in a credit line to the material. If material is not included in the article's Creative Commons licence and your intended use is not permitted by statutory regulation or exceeds the permitted use, you will need to obtain permission directly from the copyright holder. To view a copy of this licence, visit http://creativecommons.org/licenses/by/4.0/.

\section{References}

1. Spanos N, Koutsoukos PG. Kinetics of precipitation of calcium carbonate in alkaline $\mathrm{pH}$ at constant supersaturarion. Spontaneous and seeded growth. J Phys Chem B. 1998;102:6679-84.

2. Rigopoulos S, Jones A. Modeling of semibatch agglomerative gas-liquid precipitation of $\mathrm{CaCO}_{3}$ in a bubble column reactor. Ind Eng Chem Res. 2003;42:6567-75.

3. Schlomach J, Quarch K, Kind M. Investigation of precipitation of calcium carbonate at high supersaturations. Chem Eng Technol. 2006;29:215-20.

4. Sohnel O, Mullin JW. Precipitation of calcium carbonate. J Cryst Growth. 1982;60:239-50.

5. Reddy MM, Nancollas GH. The crystallization of calcium carbonate: IV. The effect of magnesium, strontium and sulfate ions. J Cryst Growth. 1976;35:33-8.

6. Kazmierczak TF, Tomson M, Nancollas GH. Crystal growth of calcium carbonate. A controlled composition kinetic study. J Phys Chem. 1982;86:103-5.

7. Jung T, Kim WS, Choi C. Effect of monovalent salts on morphology of calcium carbonate crystallized in Couette-Taylor reactor. Cryst Res Technol. 2005;40:586-92.

8. Kitano Y, Park K, Hood DW. Pure aragonite synthesis. J Geophys Res. 1962;67:4873-4.

9. Chen JF, Wang YH, Guo F, Wang XM, Zheng Ch. Synthesis of nanoparticles with novel technology: high-gravity reactive precipitation. Ind Eng Chem Res. 2000;39:948-54.

10. Feng B, Yonga AK, An $\mathrm{H}$. Effect of various factors on the particle size of calcium carbonate formed in a precipitation process. Mater Sci Eng A. 2007;445-446:170-9.

11. Montes-Hernandez G, Renard F, Geoffroy N, Charlet L, Pironon J. Rhombohedral calcite precipitation from $\mathrm{CO}_{2}-\mathrm{H}_{2} \mathrm{O}-\mathrm{Ca}(\mathrm{OH})_{2}$ slurry under supercritical and gas $\mathrm{CO}_{2}$ media. J Cryst Growth. 2007;308:228-36.

12. Wszelaka-Rylik M, Piotrowska K, Gierycz P. Simulation, aggregation and thermal analysis of nanostructured calcite obtained in a controlled multiphase process. J Therm Anal Calorim. 2015;119(2):1323-38.

13. Kedra-Krolik K, Gierycz P. Precipitation of nanostructured calcite in a controlled multiphase process. J Cryst Growth. 2009;311:3674-81.

14. Kędra-Królik K, Gierycz P, Bucki J. Controlled precipitation of $\mathrm{CaCO}_{3}$ sub-micro crystals of well-defined structure in a multiphase system. Arch Metall Mater. 2006;51:635-9.

15. Kędra-Królik K, Gierycz P. Obtaining calcium carbonate in a multiphase system by the use of new rotating disc precipitation reactor. J Therm Anal Calorim. 2006;83:579-82.

16. Guo XH, Yu SH, Cai GB. Crystallization in a mixture of solvents by using a crystal modifier: morphology control in the synthesis of highly monodisperse $\mathrm{CaCO}_{3}$ microspheres. Angew Chem Int Ed. 2006;45(24):3977-81.

17. Dizaj SM, Barzegar-Jalali M, Zarrintan MH, Adibkia K, Lotfipour F. Calcium carbonate nanoparticles as cancer drug delivery system. Expert Opin Drug Deliv. 2015;12:1649-60.

18. Saraya MEI, Rokbaa HHAL. Preparation of vaterite calcium carbonate in the form of spherical nano-size particles with the aid of polycarboxylate superplasticizer as a capping agent. Am J Nanomater. 2016;4:44-51. 
19. Peng C, Zhao Q, Gao C. Sustained delivery of doxorubicin by porous $\mathrm{CaCO}_{3}$ and chitosan/alginate multilayers-coated $\mathrm{CaCO}_{3}$ microparticles. Colloids Surf A Physicochem Eng Asp. 2010;353(2-3):132-9.

20. Ueno Y, Futagawa H, Takagi Y, Ueno A, Mizushima Y. Drugincorporating calcium carbonate nanoparticles for a new delivery system. J Control Release. 2005;103:93-8.

21. Costa LMM, Olyveira GM, Salomão R. Precipitated calcium carbonate nano-microparticles: applications in drug delivery. Adv Tissue Eng Regen Med Open Access. 2017;3:336-40.

22. Wang C, He C, Tong Z, Liu X, Ren B, Zeng F. Combination of adsorption by porous $\mathrm{CaCO}_{3}$ microparticles and encapsulation by polyelectrolyte multilayer films for sustained drug delivery. Int J Pharm. 2006;308:160-7.

23. Sukhorukov GB, Volodkin DV, Günther AM, Petrovic AI, Shenoya DB, Mohwald H. Porous calcium carbonate microparticles as templates for encapsulation of bioactive compounds. J Mater Chem. 2004;14:2073-81.

24. Dhami NK, Reddy MS, Mukherjee A. Biomineralization of calcium carbonates and their engineered applications: a review. Front Microbiol. 2013;4(314):1-13.

25. Islan GA, Cacicedo ML, Bosio VE, et al. Development and characterization of new enzymatic modified hybrid calcium carbonate microparticles to obtain nano-architectured surfaces for enhanced drug loading. J Colloid Interface Sci. 2015;439:76-87.

26. Yefimova SL, Bespalova II, Grygorova GV, et al. Synthesis and characterization of mesoporous $\mathrm{CaCO}_{3} @ \mathrm{PSS}$ microspheres as a depot system for sustained methylene blue delivering. Microporous Mesoporous Mater. 2016;236:120-8.

27. Du C, Shi J, Shi J, et al. PUA/PSS multilayer coated $\mathrm{CaCO}_{3}$ microparticles as smart drug delivery vehicles. Mater Sci Eng C Mater Biol Appl. 2013;33(7):3745-52.

28. Hakim SS, Olsson MHM, Sørensen HO, Bovet N, Bohr J, Feidenhans R, Stipp SLS. Interactions of the calcite $\{10.4\}$ surface with organic compounds: structure and behaviour at mineral-organic interfaces. Sci Rep. 2017;7:7592.

29. Liang Y, Yu K, Zheng Q, Xie J, Wang TJ. Thermal treatment to improve the hydrophobicity of ground $\mathrm{CaCO}_{3}$. Appl Surf Sci. 2018;436:832-8.

30. Jeon CW, Park S, Bang JH, Chae S, So K. Nonpolar surface modification using fatty acids and its effect on calcite from mineral carbonation of desulfurized gypsum. Coatings. 2018;8:43.

31. Cao Z, Daly M, Clémence L, Devine D. Chemical surface modification of calcium carbonate particles with stearic acid using different treating methods. Appl Surf Sci. 2016;378:320-9.

32. Fazelabdolabadi B, Alizadeh-Mojarad A. A molecular dynamics investigation into the adsorption behavior inside 001 kaolinite and 1014 calcite nano-scale channels: the case with confined hydrocarbon liquid, acid gases, and water. Appl Nanosci. 2017;7:155-65.

33. Muller BK, Ritter H. Scrutinizing ITC-study on the formation of inclusion complexes of nonionic surfactant Triton X-100 and cyclodextrins. J Incl Phenom Macrocycl Chem. 2011. https://doi. org/10.1007/s10847-011-9955-0.

34. Stojanov M, Wimmer R, Larsen KL. Study of the inclusion complexes formed between cetirizine and $\alpha-, \beta-$, and $\gamma$-cyclodextrin and evaluation on their taste-masking properties. J Pharm Sci. 2011; 100:3177-85.

35. Bouchemal K. New challenges for pharmaceutical formulations and drug delivery systems characterization using isothermal titration calorimetry. Drug Discov Today. 2008;13:960-72.

36. Castronuovo G, Niccoli M. Thermodynamics of inclusion complexes of natural and modified cyclodextrins with propranolol in aqueous solution at $298 \mathrm{~K}$. Bioorg Med Chem. 2006;14:3883-7.

37. Denadai AM, Teixeira KI, Santoro MM, Pimenta AM, Cortes ME, Sinisterra RD. Supramolecular self-assembly of beta-cyclodextrin: an effective carrier of the antimicrobial agent chlorhexidine. Carbohydr Res. 2007;342:2286-96.

38. Illapakurthy AC, Wyandt CM, Stodghill SP. Isothermal titration calorimetry method for determination of cyclodextrin complexation thermodynamics between artemisinin and naproxen under varying environmental conditions. Eur J Pharm Biopharm. 2005;59:325-32.

39. Nilsson M, Valente AJ, Olofsson G, Soderman O, Bonini M. Thermodynamic and kinetic characterization of host-guest association between bolaform surfactants and alpha- and beta-cyclodextrins. J Phys Chem B. 2007;112:11310-6.

40. Sun DZ, Li L, Qiu XM, Liu F, Yin BL. Isothermal titration calorimetry and $1 \mathrm{H}$ NMR studies on host-guest interaction of paeonol and two of its isomers with beta-cyclodextrin. Int J Pharm. 2006;316:7-13.

41. Wszelaka-Rylik M, Gierycz P. Isothermal titration calorimetry (ITC) study of natural cyclodextrins inclusion compelexes with drugs. J Therm Anal Calorim. 2013;111(3):2029-35.

42. Wszelaka-Rylik M, Gierycz P. Isothermal titration calorimetry (ITC) study of natural cyclodextrins inclusion complexes with tropane alkaloids. J Therm Anal Calorim. 2015;121(3):1359-64.

43. Wszelaka-Rylik M. Thermodynamics of $\beta$-cyclodextrin-ephedrine inclusion complex formation and covering of nanometric calcite with these substances. J Therm Anal Calorim. 2017;127:1825-34.

44. Kędra-Królik K, Wszelaka-Rylik M, Gierycz P. Thermal analysis of nanostructured calcite crystals covered with fatty acids. J Therm Anal Calorim. 2010;101(2):533-40.

45. Aki H, Niiya T, Iwase Y, Kawasaki Y, Kumai K, Kimura T. Multimodal inclusion complexes of ampicillin with $\beta$-cyclodextrin in aqueous solution. Thermochim Acta. 2004;416:87-92.

Publisher's Note Springer Nature remains neutral with regard to jurisdictional claims in published maps and institutional affiliations. 